\title{
Investigation on Criminal Psychological Incentive of University Students and Evaluation of Intervention Effect
}

\author{
Lixiang Liu ${ }^{1 *}$ \\ ${ }^{1}$ Southwest Petroleum University, Chengdu, 610500, CHINA
}

Received 26 May 2017 - Revised 31 August 2017 - Accepted 16 September 2017

\begin{abstract}
Objective: To understand the psychological factors inducing university students' illegal and criminal behavior, and provide scientific reference for provision of targeted preventive measures. Methods: A total of 680 school students were randomly selected as study objects from universities in random sampling investigation, to be divided into intervention group and control group. The intervention group received 3-month intervention to control the criminal psychological incentive, while the control group received no intervention. Results: A significant positive correlation between SCL-90 total score and 10 influencing factors $(r=0.2257 \sim 0.130 \mathrm{P}<0.001 \sim 0.05)$ was found using the self-rating symptom scale as a tool. The multi - factor LOGISTIC regression analysis of university students' psychological problems and criminal behavior found that the psychological factors affecting university students' potential criminal behavior include academic stress, love state and interpersonal relationship. After intervention, the overall mental health level increased from previous $9.8 \%$ to $88.9 \%$ in the intervention group, with statistically significant difference $(P<0.05)$, while there was no significant difference in mental health level in various dimensions before and after intervention in the control group. Conclusion: Psychological problems prevail among university students, of which, employment, love state and interpersonal relationship obviously affect university students' criminal behavior. Timely adoption of intervention measures can reconstruct the mental health system of university students and reduce the risk of crime.
\end{abstract}

Keywords: university students, crime, psychological incentive, self-rating symptom scale, intervention study

\section{INTRODUCTION}

In recent years, crime among university students has shown a spiraling trend. University student group is obviously affected by social environmental changes, and high incidence period of university students' crime is closely related to social changes. It is because university students are generally in adolescent stage. Easily impulsive and radical, they are prone to influence of external factors which contribute to criminal psychology demonstrated in criminal behavior (Yuan, 2017). University students crime is sensational in the society, the growth trend of university students' crime and the social impact are worthy of further attention (Li and Guan, 2015).

In this paper, self-rating symptom scale and LOGISTIC regression analysis model were used to analyse the correlation between psychological factors and university students' criminal behavior. On this basis, a three-month criminal psychological incentive intervention activity was conducted in 2017 to assess the intervention, specifically as follows:

\section{OBJECTS AND METHODS}

In this paper, 700 school students were selected as the investigation objects from institutions of higher learning, to be divided into intervention group and control group. 


\section{Contribution of this paper to the literature}

- Through experiment argumentation, 10 major causes to university students' crime are revealed, which provide theoretical and practical reference for prevention of university students' crime in the future.

- University students' psychologies statues are vulnerable to external factors, including family education, school education, social environment, etc. Therefore, family, school and social community should take joint effort to create healthy atmosphere, thus positively guiding university students' psychologies.

- This study provides several suggestions to release negative moods of university students, such as doing exercise, chatting with others. This study provides theoretical basis for university students to take selfregulation of mood.

Before the intervention, a total of 680 valid questionnaires were collected, accounting for $97.14 \%$ of the questionnaire. The average age was $(20.3 \pm 1)$ years. There was no significant difference in age, discipline, gender and grade of the objects surveyed.

After intervention, there were 350 students in the intervention group, with 345 valid questionnaires collected and effective rate at $98.6 \%$. There were 350 students in the control group, with 340 valid questionnaires collected and effective rate at $97.1 \%$. The average age of the intervention group was (20.26 \pm 0.54$)$ years, while that of the control group was $(20.31 \pm 0.26)$ years. There were no significant differences in gender, age, grade and discipline between the two groups.

The (SCL-90) self-rating symptom scale and self-designed psychological questionnaire were adopted in this study. In the selection of self-rating symptom scale as the main study tool, the first consideration is that the scale contains comprehensive psychological assessment contents, and can objectively and timely reflect mental health of the respondents as it is flexible in use with strong operability (Wang, 2016).

In the measurement table, single choices are for objective influencing factors, while multiple choices are for subjective influencing factors. There are 40 questions in five aspects: the first is basic information, including age, gender, major, etc.; the second is personal characteristics, including the feelings of life, daily hobbies, interpersonal relationships, health status, sleep quality, etc.; the third is family environment, mainly related information of parents, parents' education mode, family income per capita, source of living expenses, etc .; the fourth is emotional aspect, mainly love experience, love feelings, emotional confusion, etc.; the fifth is for listing of the six factors affecting psychological fluctuations. Measurement of the survey questionnaire is based on adolescent life scale. Considering actual situation of university students, objects were randomly selected for follow-up visit to understand their ideas and timely adjust the questionnaire (Zhang, 2016). Finally, according to the distribution of university students' selection rate, the ten problems that affect university students' emotional and psychological status were determined, and the intervention behavior were tracked (Zhang and Li, 2017).

Intervention period was February to May, 2017. Intervention measures for the intervention group include: (1) distributing mental health books, requiring students in the intervention group to conduct controlled self-study; (2) organizing spiritual communication activities with group as a unit, so that members have in-depth communication via mutual hearts sharing, exchange of secrets, pressure release; (3) lectures, inviting psychology lecturers, criminal psychology professors to give 5 times of special lectures for discussion of university students' criminal behavior and the role of psychological incentives in behavior; (4) For students with serious psychological problems and violence tendencies, timely compiling health manual, professional psychological counseling teacher providing one to one psychological counseling; (5) carrying out three outdoor quality expansion activities to help students relieve stress and determine goal orientation; (6) encouraging the students in the group to strengthen communication with family members, organizing activities such as school visit, letter home writing and face to face talk. The above measures were not implemented for the control group whose original teaching plan remained unchanged (Kong, 2017).

\section{Quality Control and Statistical Analysis}

Two same questionnaires were conducted among the intervention group and the control group before and after the intervention, which were filled and collected on the spot and checked by 5\% sampling (Liu, and Khine, 2016).

In the random survey, name was not left and the questionnaire was immediately recovered after on-spot investigation. Spass and Excel software was used for data induction, analysis. The impact of family factors on university students' criminal behavior was analyzed by LOGISTIC regression (Mo and Ren, 2016). 
Table 1. The top ten psychological problems that impact university students' dangerous behavior most

\begin{tabular}{ccc}
\hline Problems & Number of people & Selection rate (\%) \\
\hline Difficulty in getting along with others & 149 & 24.9 \\
\hline Employment pressure & 296 & 50.7 \\
\hline Academic pressure & 254 & 43.9 \\
\hline Graduate school exam & 237 & 41.6 \\
\hline Poor economic condition & 179 & 33.8 \\
\hline Loneliness & 145 & 23.8 \\
\hline Discrimination, misunderstanding by others & 407 & 70.1 \\
\hline Lack of interest in the major & 144 & 23.7 \\
\hline
\end{tabular}

Table 2. SCL-90 survey result, abnormal number and incidence of test students

\begin{tabular}{ccccc}
\hline SCL-90 & Factor score $(\mathbf{x} \pm \mathbf{s})$ & Abnormal number & Incidence & Ranking \\
\hline Somatization & $1.51 \pm 0.49$ & 71 & 12.03 & 10 \\
\hline Compulsion & $1.91 \pm 0.63$ & 158 & 31.3 & 1 \\
\hline Interpersonal relationship & $1.82 \pm 0.66$ & 148 & 24.59 & 3 \\
\hline Hostility & $1.74 \pm 0.49$ & 103 & 19.07 & 5 \\
\hline Anxiety & $1.62 \pm 0.61$ & 96 & 15.99 & 7 \\
\hline Depression & $1.70 \pm 0.88$ & 126 & 20.34 & 4 \\
\hline Horror & $1.37 \pm 0.81$ & 89 & 12.01 & 6 \\
\hline Paranoid & $1.61 \pm 0.63$ & 110 & 18.96 & 8 \\
\hline Psychoticism & $1.59 \pm 0.61$ & 86 & 12.98 & \\
\hline
\end{tabular}

\section{RESULTS}

\section{The Top Ten Psychological Problems that Impact University Students' Dangerous Behavior Most}

Selection rate in Table 1 can reflect current university students' most subjective, most direct psychological feelings and emotional conditions. Regarding the most important psychological factors affecting university students, whether it is fear for present or future, employment, academic pressure, love state are the most important factors. Fear of failure, fear of others' despise, ridicule and worry about getting along with others reflect the sensitive aspect of daily psychological situation of university students. Moreover, more than thirty percent of university students need to face the psychological pressure brought about by poor economic conditions (Bhagat, et al., 2017).

In the self-rating symptom scale, SCL-90 factor score $>2$ points indicates psychopathological significance. In this survey, a total of 186 people were found to have at least one meaningful factor score, accounting for $27.4 \%$ of the individuals. The results are shown in Table 2.

SCL-90 test results of 680 students: somatization, compulsion, interpersonal relationship, depression, anxiety, hostility, horror, paranoid, psychoticism factors were above the normal level, among which interpersonal sensitivity, depression, compulsion factor score are higher than those of other factors.

\section{Analysis on the Correlation between Psychological Problems and University Students' Criminal Behavior}

The single factor analysis of the survey data shows that total average score of SCL-90 in introverted university students with rude family education and lacking hobbies is significantly lower than that of similar factors, with significant difference $(\mathrm{F}=3.44 \sim 12.39, \mathrm{P}<0.05 \sim 0.0001)$.

Person research, test method found that there were significant correlations between the three objective factors of family education mode, introverted character and poor physical condition $(\mathrm{r}=0.1419 \sim 0.1213 ; \mathrm{P}=0.05 \sim 0.01)$; significant positive correlation was found between employment, study and graduate school exam $(\mathrm{r}=0.2006 \sim 0.124$ $\mathrm{P}<0.001 \sim 0.01$ ); also, significant positive correlation was found between interpersonal stress and others' mocking and misunderstanding $(\mathrm{r}=0.199 \mathrm{P}<0.001)$. There was a significant positive correlation between SCL-90 total average score and 10 influencing factors $(\mathrm{r}=0.2257 \sim 0.130 \mathrm{P}<0.001 \sim 0.05)$.

LOGISTIC regression model was built with university students' criminal behavior as dependent variable and the main psychological problem mentioned above as independent variable. The multi-factor LOGISTIC regression analysis [OR value] of university students' psychological problems and criminal behavior is shown in Table 3 . 
Table 3. Multi-factor LOGISTIC regression analysis [OR value] of university students' psychological problems and criminal behavior

\begin{tabular}{|c|c|c|c|c|}
\hline \multirow{3}{*}{$\begin{array}{c}\text { Factor } \\
\text { Interpersonal relationship }\end{array}$} & \multirow{2}{*}{\multicolumn{2}{|c|}{ Control group }} & \multicolumn{2}{|c|}{ Gender } \\
\hline & & & \multirow{2}{*}{$\begin{array}{c}\text { Male } \\
1.84(1.42-2.39)^{\star \star}\end{array}$} & \multirow{2}{*}{$\begin{array}{c}\text { Female } \\
1.57(1.25-1.96)^{*} \\
\end{array}$} \\
\hline & Tense & Harmonious & & \\
\hline Employment pressure & Can easily cope with it & Great pressure & $1.14(0.96-1.37)$ & $1.31(1.09-1.58)^{\star \star}$ \\
\hline economic status & Great pressure & No problem & $0.65(0.48-0.86)^{\star \star}$ & $0.73(0.54-1.01)$ \\
\hline Feeling away from home & Lonely & No feeling & $1.49(1.04-2.09)$ & $1.92(1.43-2.58)^{*}$ \\
\hline Love & Unsmooth & Smooth & $0.79(0.66-0.99)^{\star \star}$ & $1.30(0.99-1.78)$ \\
\hline
\end{tabular}

Note: ${ }^{*} \mathrm{P}<0.05,{ }^{*} \mathrm{P}<0.01$

Table 4. Comparison of Intervention Effects on Mental Health Level in Various Dimensions of Intervention Group and Control Group after Intervention

\begin{tabular}{|c|c|c|c|c|c|c|c|c|}
\hline \multirow{2}{*}{$\begin{array}{c}\text { Before and after } \\
\text { intervention } \\
\text { Group }\end{array}$} & \multicolumn{4}{|c|}{ Before intervention } & \multicolumn{4}{|c|}{ After intervention } \\
\hline & $\begin{array}{c}\text { Intervention } \\
\text { group }\end{array}$ & $\begin{array}{l}\text { Control } \\
\text { group }\end{array}$ & $\chi^{2}$ value & P value & $\begin{array}{c}\text { Intervention } \\
\text { group }\end{array}$ & $\begin{array}{l}\text { Control } \\
\text { group }\end{array}$ & $x^{2}$ value & P value \\
\hline Number of people & 343 & 337 & & & 345 & 340 & & \\
\hline Overall mental health level & $18(9.8)$ & $26(13.2)$ & 2.732 & 0.379 & 196(88.9) & $29(13.7)$ & 146.428 & 0.000 \\
\hline Emotional stability & $23(10.9)$ & $29(14.5)$ & 0.281 & 0.778 & 199(89.6) & $25(12.5)$ & 135.345 & 0.000 \\
\hline Interpersonal harmony & $13(6.9)$ & $14(7.0)$ & 3.326 & 0.153 & $178(82.2)$ & $20(9.0)$ & 124.533 & 0.000 \\
\hline Environmental suitability & $24(11.9)$ & $28(13.8)$ & 0.679 & 0.916 & $128(58.9)$ & $21(10.3)$ & 126.561 & 0.000 \\
\hline Psychological self-control & $16(8.0)$ & $18(8.0)$ & 3.315 & 0.146 & 183(83.3) & $19(9.1)$ & 171.234 & 0.000 \\
\hline
\end{tabular}

Note: Figure in () means possession rate/\%.

The results show that boys with interpersonal tension, economic pressure and unsmooth love are more prone to illegal and criminal behavior; while girls with interpersonal tension, employment pressure and loneliness are more prone to illegal and criminal behavior (Zhang, Chi and Song, 2016).

\section{Comparison of Intervention Effects on Mental Health Level in Various Dimensions of Intervention Group and Control Group after Intervention}

Mental health level in various dimensions was improved in the intervention group after intervention, with statistical significance in difference $(\mathrm{P}<0.05)$, while there was no significant difference in mental health level in various dimensions of control group before and after the intervention $(\mathrm{P}<0.05)$. See Table 4.

\section{DISCUSSION}

The general results of the above studies show that incidence of psychological problems among university students is $27.4 \%$. The results are in good agreement with the research results at home and abroad. The main psychological factors that affect potential criminal behavior of university students include academic stress, love state, interpersonal relationship (Wang, and Du, 2016).

After three months of interventions, students had a greater degree of improvement in overall mental health literacy and the four important mental health indicators, indicating that targeted counseling is effective means to help students alleviate their psychological problems. It also shows that timely adoption of intervention measures can control and eliminate psychological incentives that induce crime, so that university students' criminal behavior can be avoided as much as possible, risk of university students' crime can be lowered and social stability can be maintained (Gao, 2015).

This survey research shows that there are external factors and internal factors causing criminal psychological incentives in university students. The three months of intervention found that the following ways can be adopted to avoid criminal psychological incentives of university students:

Improve the external factors that induce criminal psychological incentives. As can be seen from the above, sensitive to the external environment, university students have certain group characteristics in that there is relatively close correlation between the external environment and their psychological factors. Therefore, it means certain significance to avoid the negative impact of the external environment and create a better external environment for university students.

It is recommended to improve the family growth environment. It is necessary for parents to guide university students' growth process, focus on their physical and mental health, take healthy and scientific education model, 
and shift the focus from academic achievement to healthy personality shaping (Tao, 2015). During university students' study outside, parents should also take appropriate means to communicate, talk with them and pay attention to their emotional changes, so that university students feel the warmth of family, and reduce the interference with behavior by negative attitude (Qiu, et al., 2016). For university students with bad behavior, parents should supervise and educate them, change their minds by persuasion to avoid their behavior intensification.

It is recommended to improve the school education environment. In the process of education for university students, universities should strengthen legal concept education, which shall not be superficial, but pleasing ways should be adopted for education and publicity in line with growth and psychological characteristics of university students, so that students keep legal knowledge in mind, stay away from the "high voltage line" of crime, learn to calculate the cost of crime, and know how to use law to evaluate and choose their own behavior (Yoshiro, 2014).

It is recommended to strengthen the construction of psychological counseling agencies. Universities should strengthen the construction of mental health counseling agencies, timely introduce resources, instruct students to face their own psychological problems through scientific and healthy way, timely resolve doubts and eliminate mental illness. In the process of providing psychological counseling services, efforts should be made in registration, filing, tracking visits, file management and privacy protection (Kang and David, 2014) to provide university students with a site to truly relax the mind and positively face oneself. Students should be encouraged to seek external help to reduce or even eliminate negative psychological factors, thus developing correct code of conduct.

It is recommended that university students should face up to psychological problems. Strong external factors can only play a role through action on internal factors, so students should learn to face up to their own psychological problems, know self-guidance, self-control to avoid negative psychological incentives.

It is recommended that university students choose the right goal. The above analysis shows that one major reason for the various psychological problems is lack of clear objectives. Once the objective of struggle is lost, university students are prone to confusion, sense of loss, which induces psychological problems and causes behavioral deviation. Therefore, university students at school should strengthen self-awareness, establish a reasonable goal based on their own conditions, and deal with various setbacks with positive and optimistic attitude, which helps overcome their psychological problems, avoid criminal behavior induced by risk-taking due to boredom.

It is recommended that university students should learn to reduce pressure, and correctly face various pressures. University students in a turning point in life face pressure from life, study and even marriage. Inability to adapt to the pressure will cause psychological deviation and induce criminal behavior in severe cases. Therefore, university students should improve the ability to resist pressure, maintain a peaceful mind which helps avoid resort to extreme behavior to vent pressure when it is difficult to reduce pressure.

It is recommended that university students learn to have emotional catharsis correctly. University students should correctly deal with their own emotional changes, taking timely emotional catharsis (Sunay, Yigit, and Mete, 2017). When facing great mental stress, they can shift emotional concerns by outdoor activities, talk with others, etc. and seeking help from psychological counselors if necessary. University students should learn that mere emotional depression will not help mental health, but timely and reasonable emotional catharsis should be taken to better return to the right track and reduce their risks of crime due to passionate impulse (Chen, 2017).

\section{CONCLUSION}

The limitation of this research is that it only belongs to experimental study on university students' criminal psychological incentives and the effect of intervention, which cannot fully represent mental health level and risk of criminal behavior of all university students in the area. In addition, this study shows that interventions are effective, but which interventions are most effective remains to be further studied. The system construction of prevention of university students' criminal psychology is a huge and complicated project, which requires the concerted efforts of all parties with combinations of measures to achieve the desired effect.

\section{REFERENCES}

Bhagat, K. K., Subheesh, N. P., Bhattacharya, B., \& Chang, C. Y. (2017). The Design and Development of Identification of Students' Misconceptions in Individualized Learning Environment (iSMILE) System. Eurasia Journal of Mathematics, Science E Technology Education, 13, 19-34.

Chen, Q. (2017). A Sociological Analysis of the Sustained and Powerful Sports in the United States. Journal of Nanjing Institute of Physical Education (Social Sciences), 3, 40-45.

Gao, W. H. (2015). Study on Social Work Action to Prevent Moving Juveniles' Crimes - Taking Kunming F Community as an Example. Journal of Zhejiang Gongshang University, 4, 117-128. 
Kang, H. K., \& David, L. B. (2014). Effects of Racial Discrimination, Childhood Trauma, and Trauma Symptoms on Juvenile Delinquency in African American Incarcerated Youth. Journal of Aggression, Maltreatment E Trauma, 23, 1109-1125.

Kong, H. Y. (2017). Status quo survey of criminal adolescents' active psychological quality and education countermeasures. Chinese Journal of Special Education, 5, 44-48.

Li, M., \& Guan, S. F. (2015). On the Improvement of College Students' Crime Prevention Pattern by Joint Inspection. Journal of Wuhan University of Technology (Social Science Edition), 2806, 1154-1158.

Liu, Y., \& Khine, M. S. (2016). Content Analysis of The Diagrammatic Representations of Primary Science Textbooks. Eurasia Journal of Mathematics, Science \& Technology Education, 12, 1937-1951.

Mo, R., \& Ren, H. (2016). Necessity and feasibility of psychological intervention mechanism in juvenile criminal trial. Journal of South China Normal University (Social Science Edition), 6, 139-144.

Qiu, F. F., Jiang, L., Chen, X. L, Xue, H. L., He, Y., Huang, X. H., \& Hu, Y. (2016). Correlation Analysis of Psychological Toughness and Mental Health of College Students in Hangzhou. Chinese Journal of School Health, 11, 56-58.

Sunay, F., Yigit, I., \& Mete, K. (2017). Gulmen. Results of domestic migration on juvenile delinquency in Adana, Turkey. Journal of Forensic and Legal Medicine, 49, 346-354.

Tao, X. D. (2015). Prevention of juvenile delinquency: Hong Kong experience and its implications. Contemporary Youth Research, 4, 114-119.

Wang, H. Y. (2016). Study on type, causes and countermeasures of college students' crime in China's social transformation period. Educational exploration, 5, 150-152.

Wang, X. Y., \& Du, Z. C. (2016). A new perspective towards juvenile delinquency reflected by multiple homicide cases. Issues on Juvenile Crimes and Delinquency, 3, 50-56.

Yoshiro, O. (2014). Juvenile Delinquency and Challenges of Child and Adolescent Mental Health and Juvenile Justice in Japan. Adolescent Psychiatry, 4, 270-277.

Yuan, X. (2017). Analysis of Frustration Education and Causes of College Students' Crimes. Journal of Chongqing University (Social Science Edition), 4, 23-26.

Zhang, L. (2016). Research on Criminal Psychology Education Strategy Based on Crime Cases - Comment on "Criminal Psychoanalysis and Correction". Journal of the Chinese Society of Education, 10, 111.

Zhang, L. X., \& Li, M. J. (2017). Discrimination of Criminal Responsibility Based on Criminal Psychoanalysis. Journal of Chinese People's Public Security University (Social Sciences Edition), 33, 17-24.

Zhang, Q. R., Chi, P. P., \& Song, Z. M. (2016). Study on Juvenile Delinquency Prevention from the Perspective of Social Control Theory. Journal of Yunnan Nationalities University (Social Sciences), 3304, 118-121.

\section{http://www.ejmste.com}

